\title{
ANÁLISE DA TRANSFERÊNCIA DE CALOR DURANTE O RESFRIAMENTO DE CILINDROS DE TRABALHO DA LAMINAÇÃO A QUENTE DE PLANOS
}

\author{
Marcio Rodrigo Solimani ' \\ Ronaldo Antonio Neves Marques Barbosa ${ }^{2}$ \\ Hormando Leocadio Junior ${ }^{3}$
}

\section{Resumo}

O resfriamento de cilindros na laminação a quente de planos afeta diretamente duas características fundamentais dos cilindros: a durabilidade, devido ao desgaste com a degradação da superfície, e o coroamento térmico relacionado à forma do material, devido à expansão térmica dos cilindros. $O$ resfriamento se faz através de jatos de água convenientemente ajustados. A determinação dos coeficientes de transferência de calor é fundamental para fins de otimizar o processo de resfriamento de cilindros visando aumentar sua durabilidade e a qualidade do produto laminado. Neste trabalho são apresentados resultados de estudos experimentais e numéricos dos efeitos do resfriamento através de um jato de água em formato de leque sobre um cilindro protótipo sob temperaturas entre $50^{\circ} \mathrm{C}$ e $350^{\circ} \mathrm{C}$. A pressão da água, o tipo de bico e a posição ao longo do comprimento do leque (centro e extremidade) influenciam na eficiência do resfriamento de cilindros. O valor máximo encontrado do coeficiente de transferência de calor é de $6,0 \mathrm{~kW} / \mathrm{m}^{2} .{ }^{\circ} \mathrm{C}$, sendo observada uma diferença de $14,3 \%$ entre o centro e a extremidade do leque.

Palavras-chave: Cilindro de trabalho; Laminação a quente; Resfriamento; Coeficiente de transferência de calor.

\section{ANALYSIS OF HEAT TRANSFER OF WORK ROLL COOLING IN HOT ROLLING}

\begin{abstract}
The roll cooling in Hot Rolling of flats directly affects two fundamental characteristics of the rolls:.the durability due to surface degradation. The other is the thermal expansion, which affects the shape and dimensions of the strip. Cooling is done by water jets that need to be properly adjusted. The determination of heat transfer coefficients is essential to optimize the process and thus increase its durability and quality of the strip. Results of experimental and numerical effects of cooling using a water jet fan-shaped on a prototype roll at temperatures between $50^{\circ} \mathrm{C}$ and $350^{\circ} \mathrm{C}$ are performed. Water pressure, nozzle type and the position along the length of the fan-shaped (center and edge) influence the efficiency of roll cooling. The maximum value found in the coefficient of heat transfer was $6.0 \mathrm{~kW} / \mathrm{m}^{2} .{ }^{\circ} \mathrm{C}$, and a $14.3 \%$ difference between the center and end of the jet fan-shaped is observed.

Key words: Work roll; Hot rolling; Cooling; Heat transfer coefficient.
\end{abstract}

\footnotetext{
'Engenheiro Metalurgista. Mestre, Membro da ABM, Gerente do Acabamento de Tiras a Quente e Oficinas de Cilindros, Usiminas, Av. Pedro Linhares Gomes, 543I, Usiminas, Cep 35 160-900, Ipatinga, MG, Brasil. E-mail: marcio.solimani@usiminas.com ${ }^{2}$ Engenheiro Mecânico, Doutor. Membro da ABM, Professor Associado do Departamento de Engenharia Metalúrgica e de Materiais, Universidade Federal de Minas Gerais - UFMG, Av. Antônio Carlos, 6627, Escola de Engenharia - Bloco 2, Secretaria, sala 2233, Pampulha, Cep 31270-90I, Belo Horizonte, MG, Brasil. E-mail: rbarbosa@demet.ufmg.br

${ }^{3}$ Engenheiro Mecânico, Mestre, Membro da ABM, Pesquisador Especialista da Superintendência de Pesquisa e Desenvolvimento, Usiminas, Av. Pedro Linhares Gomes, 543I, Usiminas, Cep 35160-900, Ipatinga, MG, Brasil. E-mail: hormando.leocadio@usiminas.com
} 


\section{INTRODUÇÃO}

Devido ao contato direto com o material a ser processado, os cilindros de trabalho são componentes relevantes na produção de laminados a quente de planos, por serem um dos principais responsáveis por sua forma e acabamento superficial. Pela sua significância nos custos de bobinas, destacam-se como elementos de grande importância. A vida útil dos cilindros de laminação é limitada pela degradação e desgaste de sua superfície durante os seus ciclos de operação de laminação.

Essa degradação, seguida de desgaste, modifica a sua condição original, a sua geometria e a sua rugosidade superficial. As mudanças na geometria do cilindro, combinadas com a expansão térmica, afetam o perfil e a forma dos laminados. Outro aspecto do desgaste é que, quando suficientemente alto, a carepa terciária, desenvolvida após a descarepação primária, acumula nas cavidades da superfície do cilindro e posteriormente passa a ser impressa na superfície das tiras laminadas, gerando o defeito superficial chamado de carepa de cilindro.(I) Nesse contexto, o resfriamento aplicado adequadamente influencia a vida útil dos cilindros e, consequentemente, na qualidade dos produtos.

Como o aquecimento não é uniforme ao longo da mesa do cilindro e ao longo do tempo, a variação dimensional resultante não é linear, gerando tensões térmicas que podem provocar a formação de trincas que danificam os cilindros, gerando defeitos superficiais nos produtos laminados ou até mesmo a fratura dos cilindros. Além disso, outro problema relacionado ao aquecimento e a expansão térmica dos cilindros é a variação da espessura do produto laminado ao longo da largura.

A geração de trincas e o descontrole da coroa térmica nos cilindros podem ser evitadas ou atenuadas mediante um resfriamento adequado. Esse resfriamento é feito com jatos de água sobre a sua superfície. Para efetividade do resfriamento não basta lançar água em abundância sobre os cilindros: é preciso que os jatos sejam distribuídos convenientemente no cilindro e com a pressão adequada de acordo com a área, ou seja, na vazão suficiente para remover a quantidade de calor na medida certa. Entretanto, o resfriamento de cilindros é um problema complexo, que mesmo muito estudado ainda traz incertezas, principalmente quanto à determinação dos coeficientes de transferência de calor.

\section{I.I Sistema de Resfriamento de Cilindros na Laminação a Quente}

Em princípio, no processo de resfriamento, o volume de água deve ser adequado e a pressão ajustada de tal forma que cada ponto da superfície do cilindro ceda máxima quantidade de calor à água refrigerante minimizando a penetração do calor na massa dos cilindros, ${ }^{(2)}$ mantendo a temperatura dentro de uma faixa de controle.
O sistema de resfriamento é constituído de headers ou cabeçotes, montados paralelamente aos cilindros, com bicos adaptados para direcionar os jatos de água. Esses jatos normalmente são aplicados sobre os cilindros em forma de leque, na quantidade e na distribuição necessárias. A alta pressão, a água proporciona o rompimento da camada de calefação formada sobre os cilindros passando a remover eficientemente a quantidade de calor em excesso que tenderia a se acumular nos cilindros. A adequação da distância, a orientação e inclinação dos jatos de água entre outros determinam a eficiência dos sistemas de resfriamento.

Em cadeiras de laminação de grande redução e velocidade periférica baixa, onde o trabalho é mais crítico, será aconselhável o emprego de maiores volumes e pressões de água. As pressões utilizadas em laminadores acabadores, segundo Kerr,* variam entre $8,5 \mathrm{kgf} / \mathrm{cm}^{2}$ e $13 \mathrm{kgf} / \mathrm{cm}^{2}$, podendo alcançar $15,5 \mathrm{kgf} / \mathrm{cm}^{2}$.

O coeficiente de transferência de calor depende da temperatura superficial do cilindro e das características do jato de água. ${ }^{(3)}$ Barbadillo e Trozzi, ${ }^{(4)}$ acrescentam a densidade do jato de água como item importante que afeta o coeficiente convectivo. $O$ resfriamento de uma superfície aquecida, descrito por Shiina, Nakamura e Narita ${ }^{(5)}$ (Figura I), apresenta formação de zonas distintas: zona de impacto do jato (II), em seguida zona de nucleação de bolhas (NB), zona de transição (ZT) e filme de vapor (FV), com características distintas em termos de trocas térmicas.

Para o estudo do comportamento térmico dos cilindros de trabalho foi construído um sistema em escala piloto para o resfriamento de um cilindro protótipo para simular as condições térmicas, proporcionando a aquisição de informações para fins de melhorias no sistema atual de resfriamento, compreendendo, avaliando e medindo os fenômenos da transferência de calor e, com análise dos resultados de simulação, comparar bicos a serem utilizados nos headers de resfriamento.

\section{MATERIAIS E MÉTODOS}

A Figura 2 mostra o aparato experimental desenvolvido e montado na Oficina de Cilindros do Tiras a Quente da Usiminas - Usina de Ipatinga. É um protótipo em escala piloto de um sistema de resfriamento de cilindros desenvolvido a fim de observar os fenômenos durante o resfriamento e coletar dados para determinar o coeficiente de transferência de calor. O cilindro protótipo consiste em um tubo de aço SAE 1020, que é uma simplificação em relação ao cilindro maciço real na linha de laminação. Isto, entretanto, é razoável do ponto de vista da transferência de calor porque as variações de temperaturas medidas neste trabalho restringem-se à superfície do tubo, como de fato é o caso na laminação industrial.

\footnotetext{
* Kerr EJ. Plant visit to Usiminas-ILQT. Metallurgical Engineering Services to the Steel Industry. Ipatinga; 2004. (Relatório interno).
} 
O tubo de aço foi fixado em um eixo e montado sobre um tanque. $\mathrm{O}$ eixo foi acoplado e acionado por um sistema de redutora e motor. $\mathrm{O}$ header com o bico de resfriamento foi fixado na extremidade do tanque e ajustada para ficar a $90^{\circ}$ do eixo do cilindro. Na parte contrária ao tubo do resfriamento foi montado outro tubo com os bicos para o aquecimento.

O combustível utilizado foi o acetileno com ar comprimido para o aquecimento do tubo cilíndrico. As temperaturas foram medidas através de termopares e sistema de aquisição de dados, via wireless, composto por

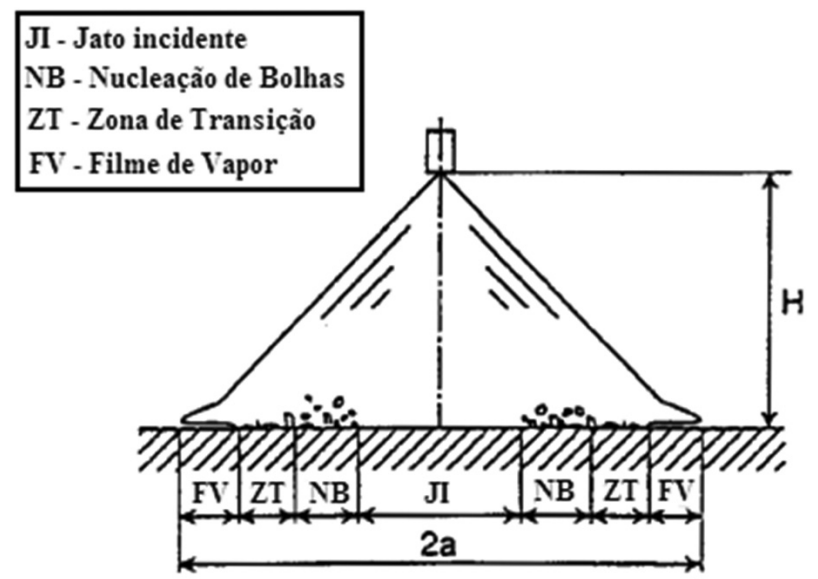

Figura I. Características do leque durante o impacto em uma superfície quente. ${ }^{(5)}$ transmissor de dados; condicionador de sinal; computador com interface wireless e software desenvolvido pelo Laboratório de Desenvolvimento Tecnológico da Usiminas. Ao condicionador de sinal, foram conectados os termopares (tipo K) cujas juntas de medição foram montadas no cilindro protótipo em posições definidas. $\mathrm{O}$ cilindro protótipo com dimensões de $900 \mathrm{~mm}$ de comprimento, diâmetro externo de $352 \mathrm{~mm}$, e com parede de $16 \mathrm{~mm}$ de espessura tinha as furações para os termopares conforme apresentado nas Figuras $3 \mathrm{a}$ e $3 \mathrm{~b}$. Os termopares foram colocados de tal modo que as juntas de medições distavam $2 \mathrm{~mm}$ da superfície do cilindro. Durante os testes foram usados três bicos, com jatos em formato de leque ( $\mathrm{A}, \mathrm{B}$ e $\mathrm{C}$ ). Os bicos usados possuem vazões diferentes numa mesma pressão e ângulos de leque diferentes $110^{\circ} \mathrm{e}$ $65^{\circ}$. Cada um foi montado em uma tubulação (Figura 3c).

\section{I Procedimento Experimental}

Os experimentos consistiram em aquecer o cilindro protótipo enquanto girava a $5 \mathrm{rpm}$. Após a temperatura superficial atingir valor superior a $300^{\circ} \mathrm{C}$, o sistema motor/bomba era acionado, iniciando o processo de resfriamento. Durante $\circ$ processo, a temperatura era monitorada por sete termopares. Foram realizados 31 ciclos de aquecimento e resfriamento, alterando pressão da água e acetileno, tipo de bico e resfriamento com e sem o aquecimento. As coletas de dados geraram curvas de "temperatura $\times$ tempo" dos ciclos (Figura 4).

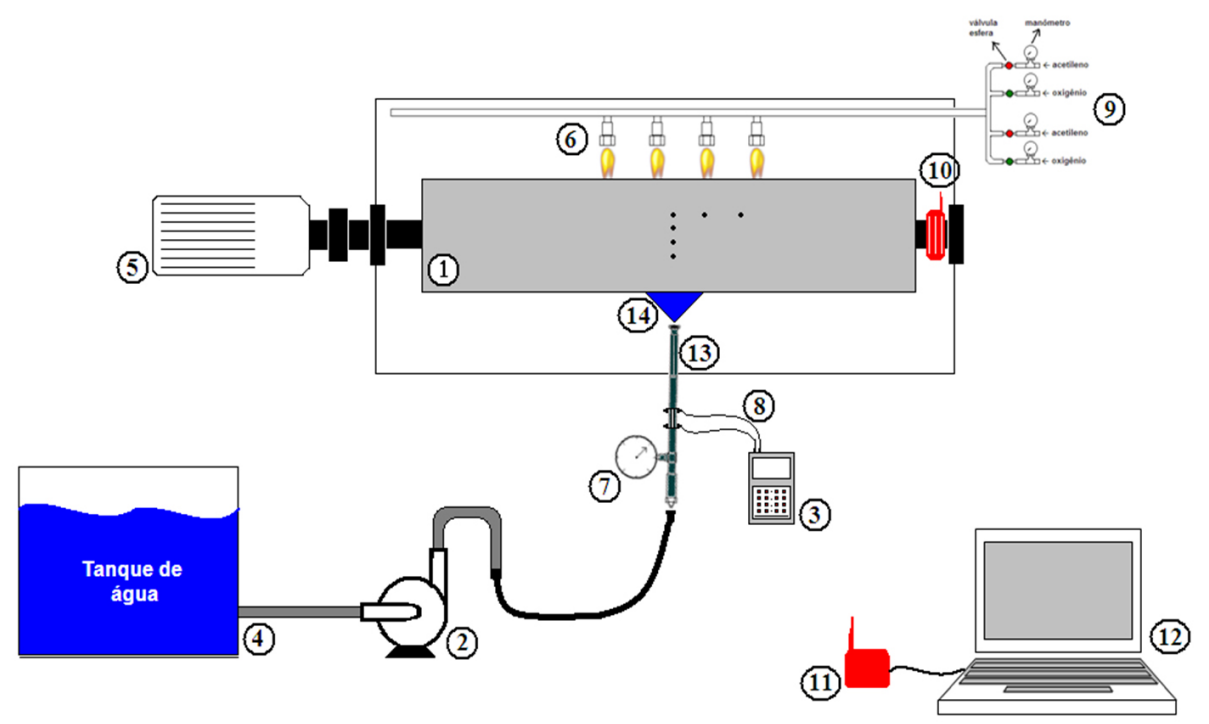

1. Tubo de aço SAE1020.
3. Medidor de vazão.
5. Motor e redutora.
7. Medidor de pressão.
9. Ar e acetileno.
11. Condicionador de sinal.
13. Header ou cabeçote.

2. Conjunto motor-bomba.

4. Caixa d'água.

6. Tubulação para aquecimento

8. Termopares tipo K.

10. Transmissor de dados.

12. Computador.

14. Jato de água.

Figura 2. Representação esquemática de aparato utilizado nos experimentos realizados neste trabalho. 


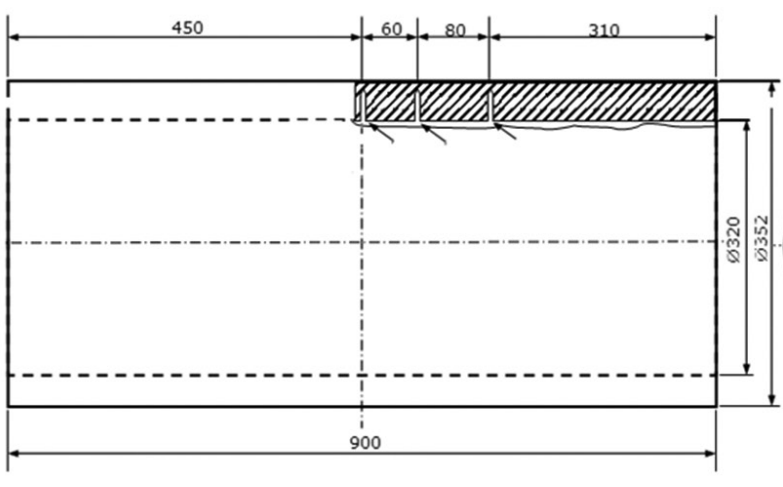

(a)

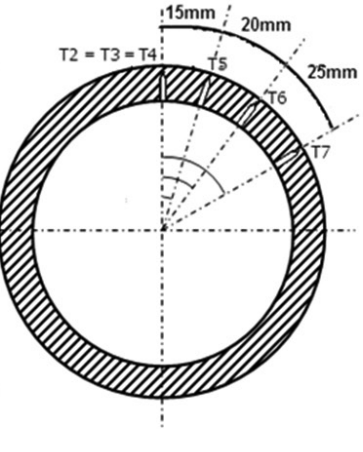

(b)

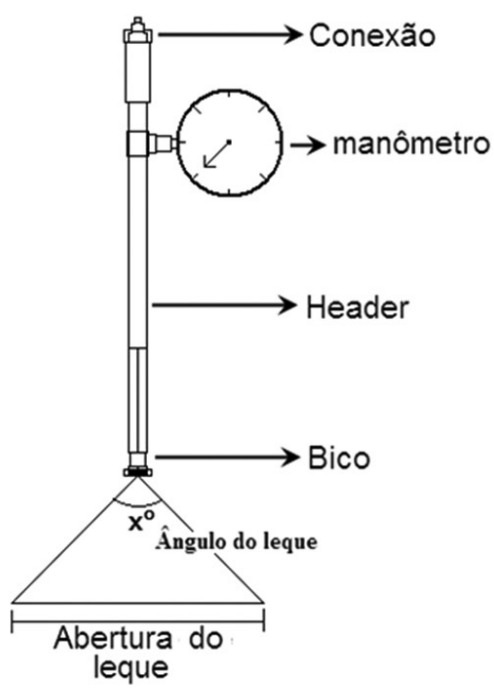

(c)

Figura 3. (a) e (b) Cilindro protótipo e (c) montagem do header para os testes de resfriamento.

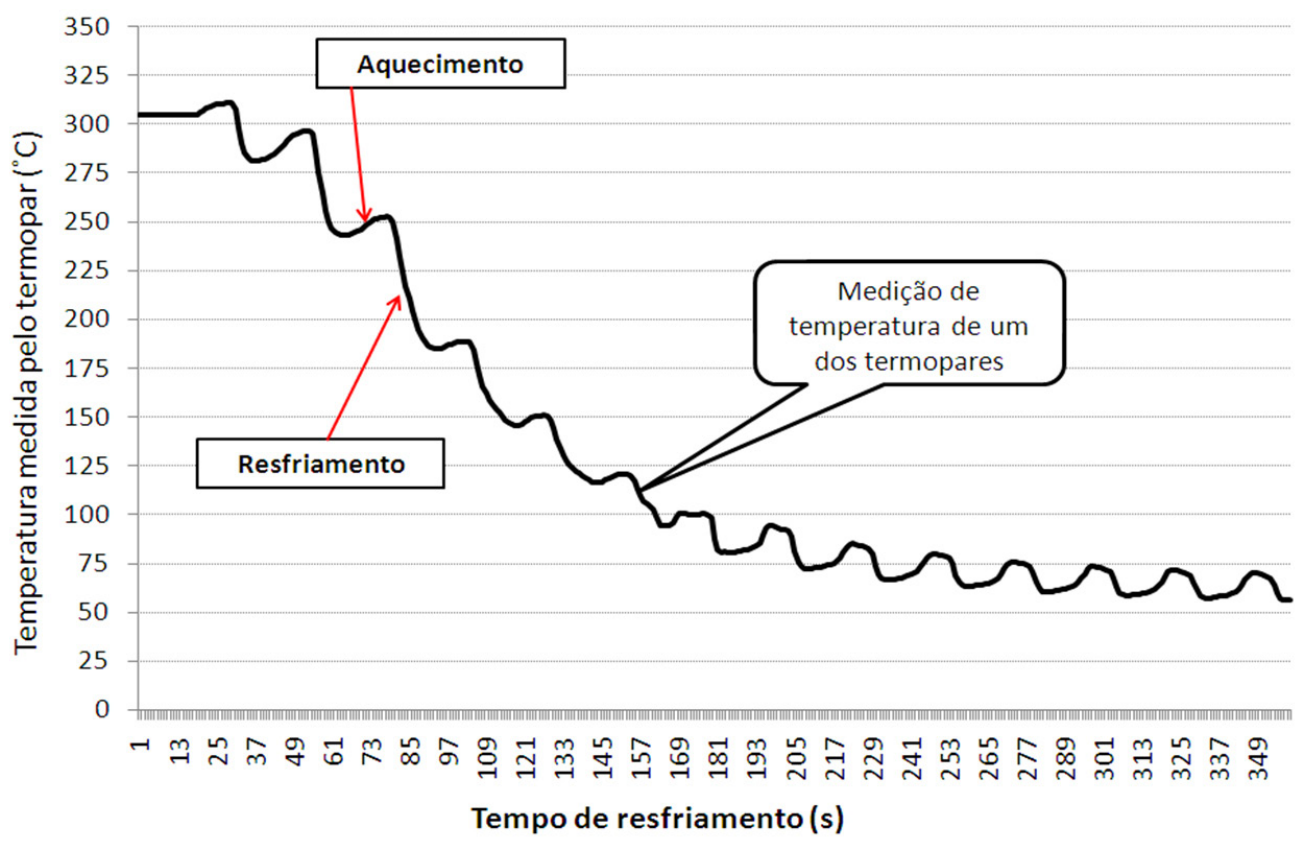

Figura 4. Temperatura em função do tempo em um dos experimentos realizados.

\subsection{Análise Inversa de Condução de Calor}

Foi realizada análise inversa de condução de calor transiente, a fim de se calcular o histórico de temperaturas e os fluxos de calor na superfície do cilindro protótipo, a partir das temperaturas medidas durante os testes. $O$ software usado combina as temperaturas medidas para estimar os fluxos de calor aplicados na superfície.

Para a análise inversa de condução de calor transiente foram utilizados modelos de elementos finitos em 2D, planar, com elementos quadráticos e triangulares variando de $0,5 \mathrm{~mm}$ a I $\mathrm{mm}$. O modelo foi construído a partir de uma porção do cilindro protótipo, que contemplava $\circ$ posicionamento de três termopares, Tc4, Tc3 e Tc2, posicionados justamente no centro e nas extremidades dos leques formados (ângulos de $65^{\circ}$ e $110^{\circ}$ ), conforme apresentado na Figura 5.

O detalhe da malha formada e a indicação do fluxo de calor na superfície do cilindro protótipo são mostrados na Figura 6. A malha do modelo foi constituída de 4.79 I nós e 4.770 elementos quadráticos e triangulares, para uma parcela do cilindro protótipo, mostrando as três regiões de fluxo de calor na superfície do tubo e a representação nodal dos termopares. A condição de 


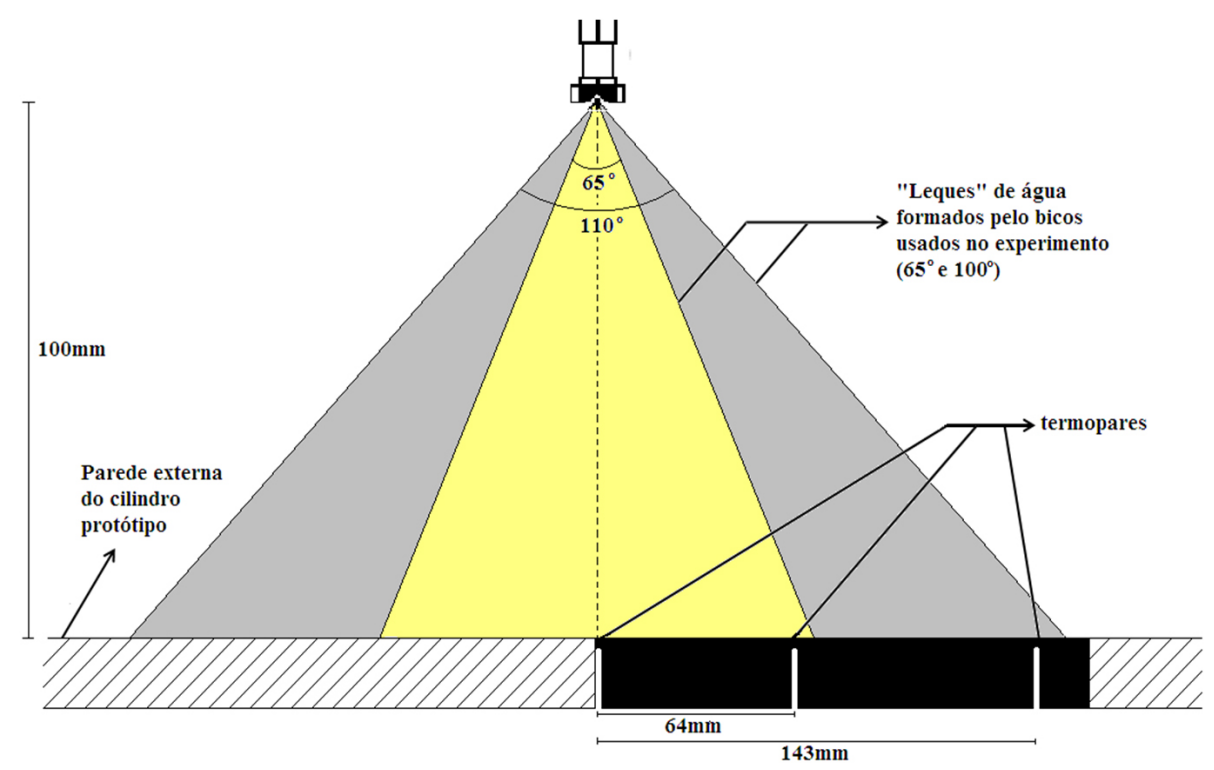

Figura 5. Essa figura representa o posicionamento dos termopares para que fiquem no centro e nas extremidades dos leques.

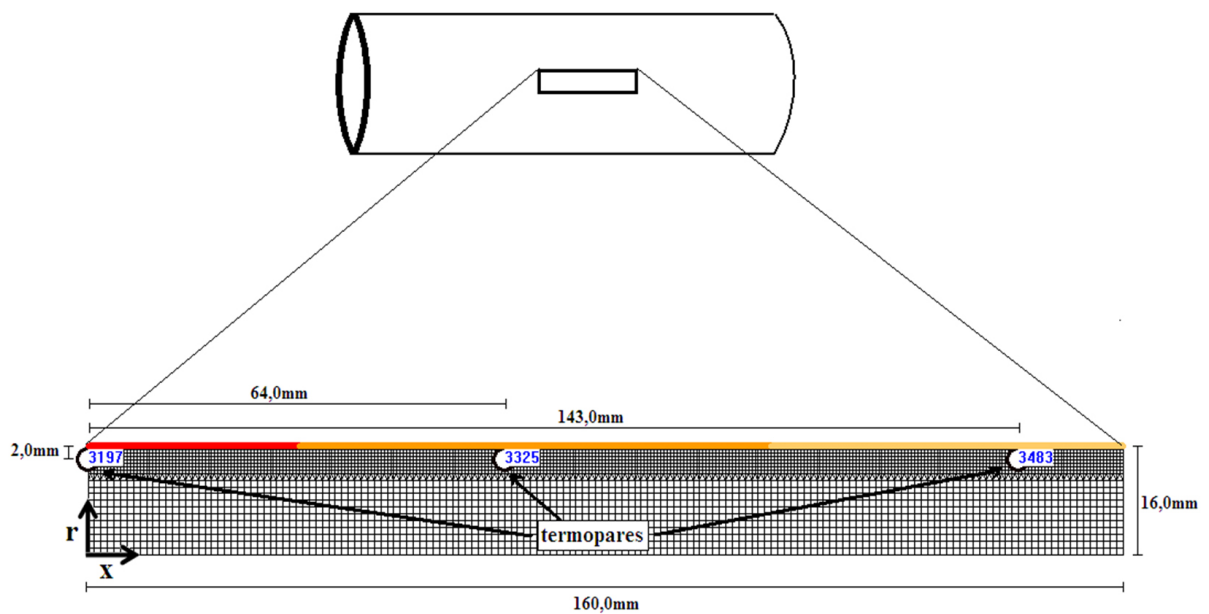

Figura 6. Modelo construído para análise inversa de condução de calor.

contorno adotada foi regime adiabático nas superfícies sem incidência do jato d'água, uma vez que as quantidades de radiação e convecção para o ambiente nessas superfícies são muito menores do que na superfície de incidência do jato.

\section{RESULTADOS E DISCUSSÃO}

\section{I Avaliação Visual do Resfriamento do Cilindro Protótipo}

Durante os testes, para avaliação visual, foram tiradas fotos do local de impacto do jato de água no decorrer do resfriamento do cilindro protótipo. Quanto menor a temperatura do cilindro protótipo maior a região de contato da água com o cilindro (molhamento), ou seja, mais as zonas de nucleação de bolhas e o filme de vapor se distanciavam do local de impacto do jato de água. Esse fato é mostrado em sequência nas Figuras $7 \mathrm{a}$ a $7 f$, descrito por Shiina, Nakamura e Narita. ${ }^{(5)}$

\subsection{Avaliação da Transferência de Calor}

Foram determinadas os valores de fluxo de calor $\left(\mathrm{kW} / \mathrm{m}^{2}\right)$, o coeficiente de transferência de calor $h$ $\left(\mathrm{kW} / \mathrm{m}^{2} .{ }^{\circ} \mathrm{C}\right)$, as temperaturas $\left(\mathrm{em}{ }^{\circ} \mathrm{C}\right)$ superficial e sub-superficial. Neste trabalho são apresentadas avaliações realizadas sobre a variação da pressão da água no centro do leque formado pelo bico projetor, bem como as variações em três pontos ao longo do seu comprimento, centro, meio e extremidade para a mesma pressão, e a influência do tipo de bico. 
O modelo fornece as isotermas do perfil térmico da região resfriada do cilindro protótipo a partir dos resultados feitos com a análise inversa de condução de calor. As isotermas no instante de $118 \mathrm{~s} \mathrm{em} \mathrm{um} \mathrm{dos} \mathrm{testes} \mathrm{reali-}$ zados são apresentadas na Figura 8. Nesse momento, a temperatura da superfície do cilindro protótipo apresenta variação entre $81{ }^{\circ} \mathrm{C}$, no momento do aquecimento, e $60^{\circ} \mathrm{C}$, no momento do resfriamento. Esta figura evidencia a condição em que o resfriamento e a perda de calor são maiores no centro do leque.

\subsection{Avaliação com diferentes pressões}

As análises foram feitas utilizando o bico A e variando a pressão em $2 \mathrm{kgf} / \mathrm{cm}^{2} ; 5 \mathrm{~kg} / \mathrm{cm}^{2} ; 10 \mathrm{kgf} / \mathrm{cm}^{2} ; 15 \mathrm{kgf} / \mathrm{cm}^{2}$ e $19 \mathrm{kgf} / \mathrm{cm}^{2}$, baseando-se nas medições do termopar Tc4 (centro do leque). O reflexo da temperatura dos ciclos de resfriamento é inferior a $10 \mathrm{~mm}$ da superfície. Em temperaturas maiores que $200^{\circ} \mathrm{C}$ a variação chega a $65^{\circ} \mathrm{C}$. Em temperaturas baixas essa variação é mínima, mantendo-se praticamente constante.

Confrontando as curvas de resfriamento dos testes, para diferentes pressões e considerando a curva do teste com pressão de $2 \mathrm{~kg} / \mathrm{cm}^{2}$ como base, obtém-se - gráfico da Figura 9, considerando os 10 primeiros ciclos de resfriamento e aquecimento. Quanto maior a pressão de resfriamento maior a queda de temperatura no ponto medido. A maior diferença encontrada é de $90,18^{\circ} \mathrm{C}$ utilizando pressão de $19 \mathrm{kgf} / \mathrm{cm}^{2}$.

Os valores máximos de fluxo de calor calculados na superfície, com temperatura superficial acima de $100^{\circ} \mathrm{C}$ estão apresentados na Figura 10. Os resultados evidenciam que o fluxo de calor é proporcional à pressão de resfriamento.

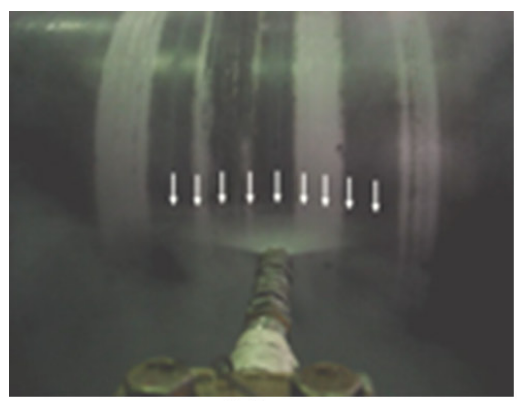

(a)

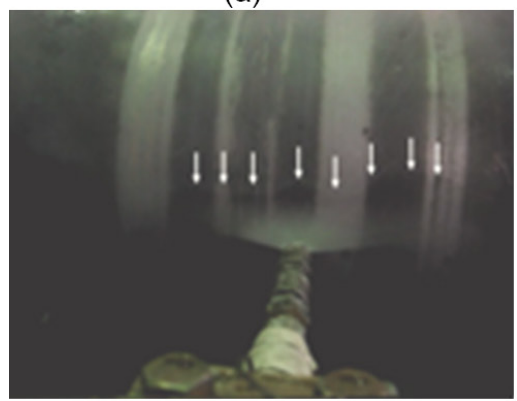

(d)

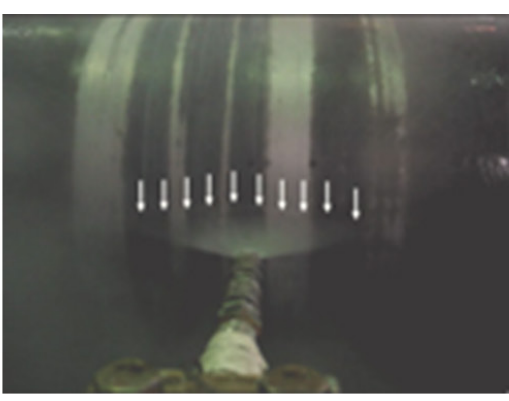

(b)

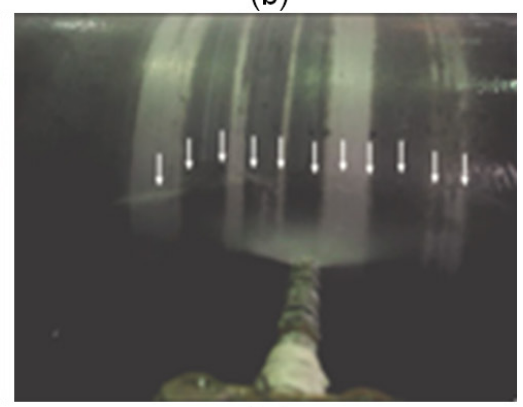

(e)

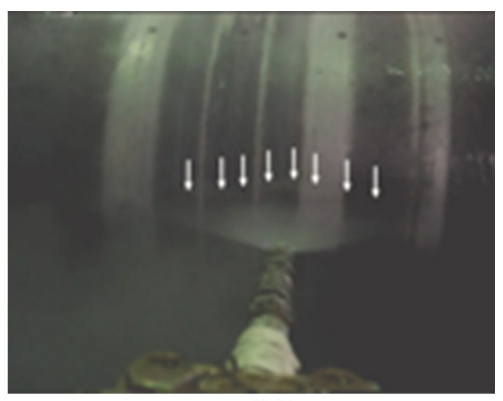

(c)

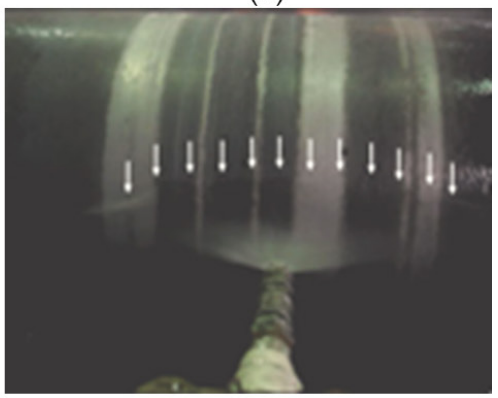

(f)

Figura 7. Fotografias do processo de resfriamento. A temperatura do cilindro protótipo é constante e igual a $300^{\circ} \mathrm{C}$ no início de todos os experimentos.

For time 1.18000E+002 Max Temp 85.0 node 121 -Min Temp 63.8 node 4473
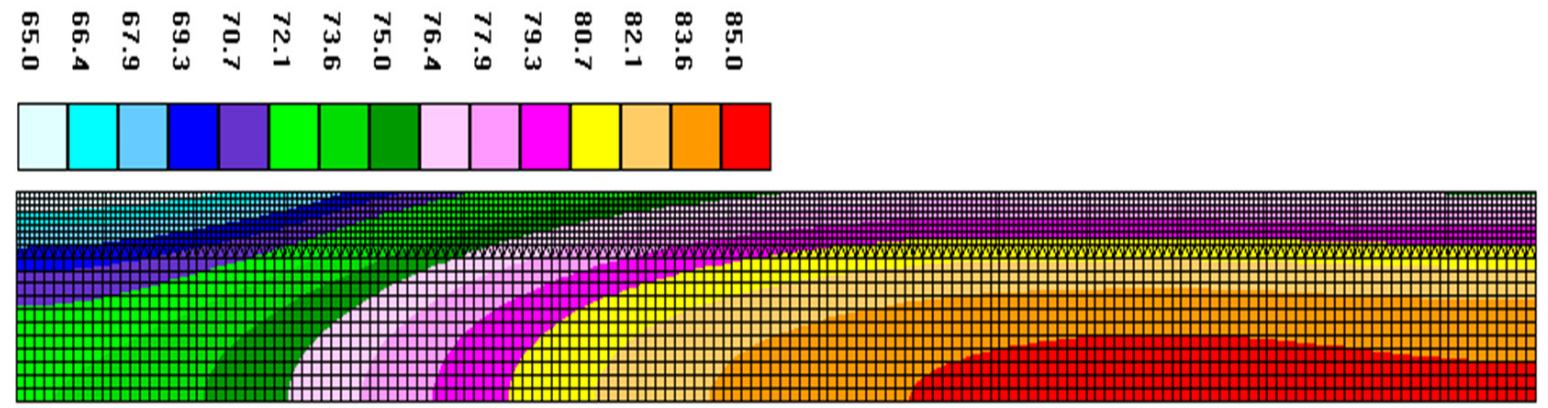

Figura 8. Isotermas no instante $t=118 \mathrm{~s}$. 
O coeficiente de transferência de calor muda de comportamento quando a superfície atinge temperatura próxima de $100^{\circ} \mathrm{C}$. Isso é explicado pelo fato de que, quando a temperatura aumenta, as bolhas na superfície são formadas mais rapidamente passando para uma região de ebulição em película onde a formação de bolhas é tão rápida que elas coalescem antes de se desprenderem da superfície. Com isso, grande parte da superfície fica coberta por uma película instável de vapor, que aumenta a resistência térmica, reduzindo o calor transferido, conforme indicado por Horský, Raudenský e Pohanka. ${ }^{(3)}$ Conforme relatado por Leocádio, ${ }^{(6)}$ o coeficiente de transferência de calor cresce até atingir a região de ebulição nucleada. A partir desse ponto, permanece constante até o início do regime de convecção forçada monofásica. Com esse regime, o coeficiente convectivo aumenta proporcionalmente à diminuição da temperatura superficial. Considerando temperaturas abaixo de $100^{\circ} \mathrm{C}$ verifica-se que o valor médio de $h$ varia com a pressão de acordo com o gráfico da Figura II.

Estes valores estão coerentes com Liu, Finn e Ramser ${ }^{(7)}$ que, também aplicando análise inversa de condução de calor, encontram valores médios de $6,50 \mathrm{~kW} / \mathrm{m}^{2} .{ }^{\circ} \mathrm{C}$, no centro do leque, e $5,0 \mathrm{~kW} / \mathrm{m}^{2} .{ }^{\circ} \mathrm{C}$, na extremidade do leque, para temperaturas abaixo de $95^{\circ} \mathrm{C}$ e com cilindro com rotação de $200 \mathrm{rpm}$. Tseng, Lin e Gunderia ${ }^{(8)}$ realizaram experimentos em um cilindro de alumínio a pressão de $13 \mathrm{kgf} / \mathrm{cm}^{2}$ encontraram $h$ o valor de $\mathrm{h}=6,0 \mathrm{~kW} / \mathrm{m}^{2} .{ }^{\circ} \mathrm{C}$, na posição central do leque, na qual o bico estava posicionado a uma distância de $7 \mathrm{~cm}$ da superfície do cilindro.

\subsubsection{Avaliação ao longo do comprimento do leque}

Neste item são apresentados os resultados de transferência de calor ao longo do comprimento do leque. São três pontos ao longo do alinhamento, centro (termopar TC4), extremidade (termopar Tc3) e um intermediário (termopar Tc2). Para avaliação, usam-se dados de pressão de resfriamento de $15 \mathrm{kgf} / \mathrm{cm}^{2}$ e bico A.

Comparando as curvas de fluxo de calor para as três regiões nos 10 primeiros ciclos de resfriamento (Figura 12), nota-se que a região do centro do lequeapresenta uma eficiência maior para altas temperaturas, mantendo-se superior comparado às outras duas regióes. Como a região do centro do leque passa por um resfriamento mais acelerado, essa região chega à temperatura próxima a $100^{\circ} \mathrm{C}$ num tempo menor. Esse fato é evidenciado no ciclo 6 , onde o fluxo volta a subir passando para a região de convecção em regime monofásico. As regiões Tc3 e Tc2 passam por essa transição somente no ciclo seguinte. Após o ciclo 8, os fluxos estabilizam-se manté-se muito próximos uns dos outros. Verfica-se então que a transferência de calor na região do centro do leque é mais intensa comparada às outras regiões do leque em análise.

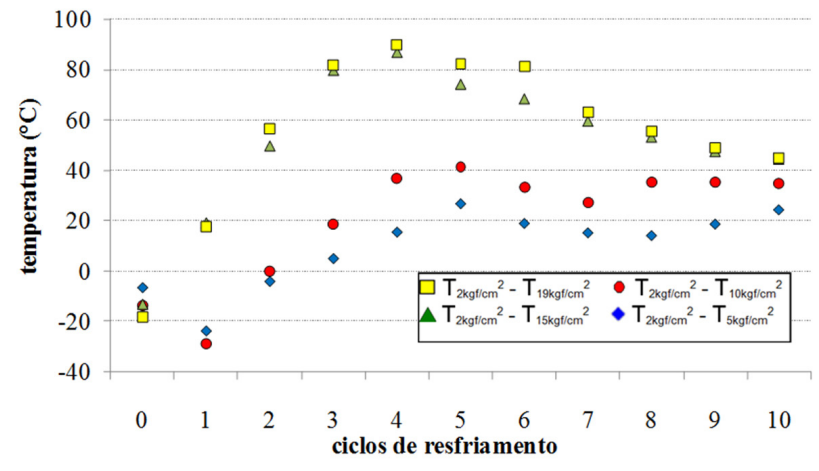

Figura 9. Diferença de temperatura entre os testes de resfriamento a diferentes pressões usando o bico $\mathrm{A}$.

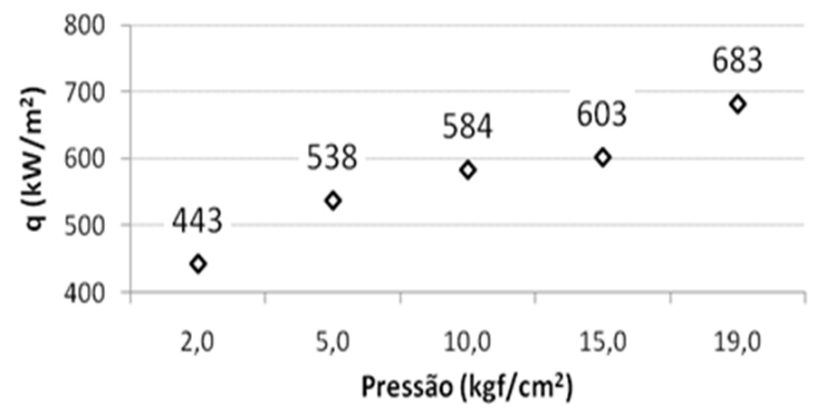

Figura 10. Valores de fluxo de calor em função da pressão.

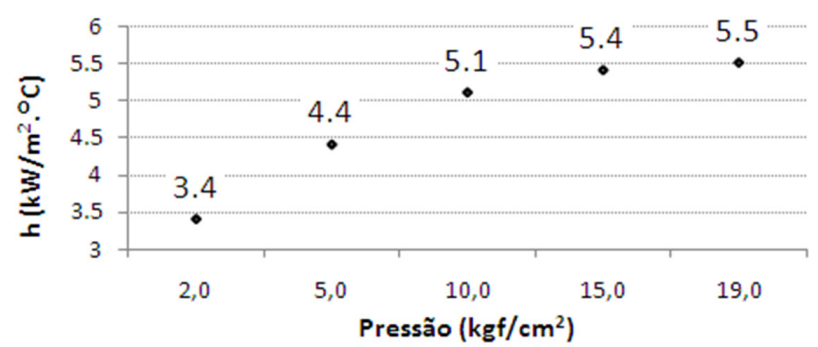

Figura I I. Valores do coeficiente de transferência de calor em função da pressão.

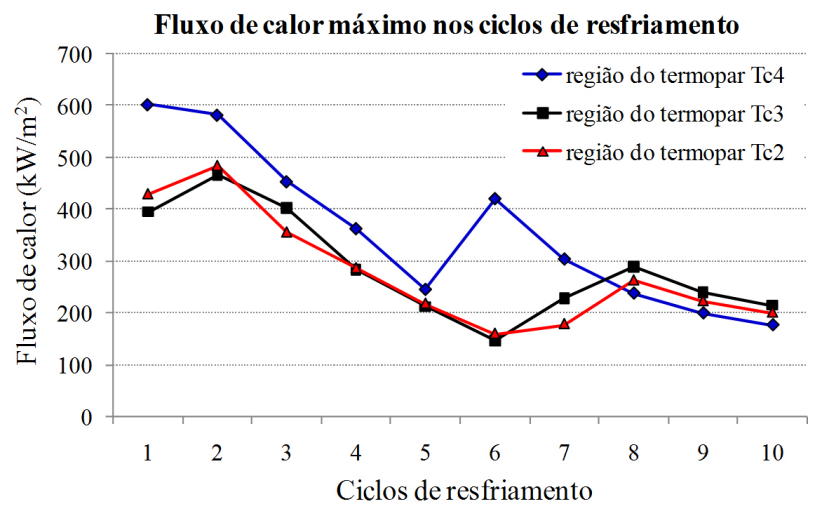

Figura I2. Fluxo de calor na superfície do cilindro protótipo com pressão de $15 \mathrm{kgf} / \mathrm{cm}^{2}$, ao longo do comprimento do leque. 


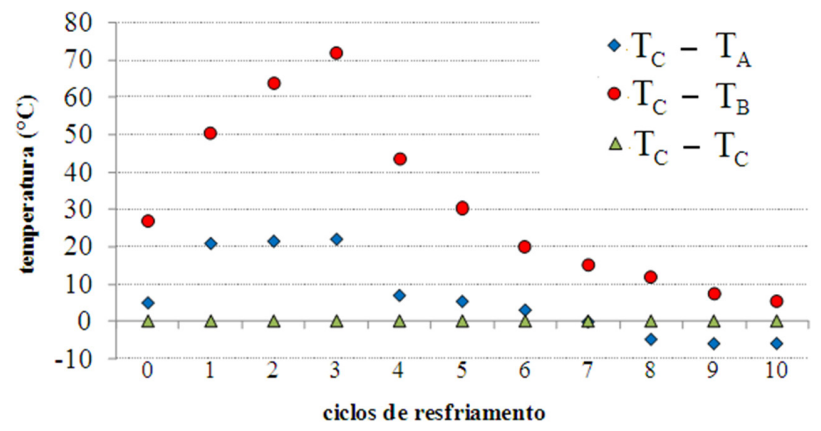

Figura 13. Diferença de temperatura entre os bicos nos ciclos de resfriamento tomando por base a curva de resfriamento usando o bico C.

Quanto maior a pressão menor a diferença entre os coeficientes de transferência de calor ao longo do comprimento do leque. Shiina, Nakamura e Narita, ${ }^{(5)}$ utilizando uma porção de um cilindro de cobre, empregando três diferentes bicos distanciados $300 \mathrm{~mm}$ da superfície, encontram valores máximos de $8,7 \mathrm{~kW} / \mathrm{m}^{2} .{ }^{\circ} \mathrm{C}$ no centro e $\mathrm{I}, 2 \mathrm{~kW} / \mathrm{m}^{2} .{ }^{\circ} \mathrm{C}$ na extremidade do leque.

\subsubsection{Avaliação com diferentes bicos}

Como relatado anteriormente os três bicos analisados são $A, B$ e $C$. Os bicos foram avaliados a uma pressão de $5 \mathrm{kgf} / \mathrm{cm}^{2}$ e os dados fcoletados no centro do leque. Utilizando como referência o bico $\mathrm{C}$ e analisando os 10 primeiros ciclos de resfriamento, verifica-se que, no decorrer do resfriamento, a diferença de temperatura entre os testes vai aumentando até 0 ciclo de resfriamento 3 (bico $\mathrm{A}=204,6^{\circ} \mathrm{C}$, bico $\mathrm{B}=154,9^{\circ} \mathrm{C}$ e bico $\mathrm{C}=226,6^{\circ} \mathrm{C}$ ) (Figura I3), chegando a uma diferença de $71^{\circ} \mathrm{C}$, indicando maior eficiência na extração de calor, pelo bico $B$.

As diferenças de temperaturas proporcionadas pelo bico $B$ em relação aos bicos $C$ e $A$ deve-se ao maior volume de água $(\mathrm{L} / \mathrm{cm} 2$. min) lançada pela área de projeção do bico. Os valores máximos de fluxo de calor calculados na superfície são de $613,75 \mathrm{~kW} / \mathrm{m}^{2}$, para o bico $B$, de
$578,01 \mathrm{~kW} / \mathrm{m}^{2}$, para o bico C, e de $538,40 \mathrm{~kW} / \mathrm{m}^{2}$, para o bico $A$. Esses valores mostram novamente que, através do bico $\mathrm{B}$, há maior transferência de calor em comparação aos outros dois bicos testados. Percebe-se ainda que o coeficiente de transferência de calor também apresenta mudança de comportamento quando a temperatura da superfície aproxima-se de $100^{\circ} \mathrm{C}$. Fazendo-se comparativo do coeficiente convectivo para temperaturas menores que $100^{\circ} \mathrm{C}$, já que nessas temperaturas não há formação de bolhas, ou seja, o regime é monofásico, os valores de $\mathrm{h}$ são: bico $B=6,01 \mathrm{~kW} / \mathrm{m}^{2} .{ }^{\circ} \mathrm{C}$; bico $\mathrm{C}=5,56 \mathrm{~kW} / \mathrm{m}^{2} .{ }^{\circ} \mathrm{C}$ e bico $A=5,23 \mathrm{~kW} / \mathrm{m}^{2} .{ }^{\circ} \mathrm{C}$.

\section{CONCLUSÃO}

Para a análise da transferência de calor foi usado um tubo de aço SAE 1020 de $16 \mathrm{~mm}$ de espessura, $360 \mathrm{~mm}$ de diâmetro e $900 \mathrm{~mm}$ de comprimento, que foi aquecido a temperaturas próximas a $300^{\circ} \mathrm{C}$ e resfriado através de bico projetor com pressões da água variando de $2 \mathrm{kgf} / \mathrm{cm}^{2}$ a $19 \mathrm{~kg} / \mathrm{cm}^{2}$. Durante o processo, o sistema girava a uma velocidade constante de $5 \mathrm{rpm}$. A transferência de calor durante o resfriamento de cilindros é sensível à pressão, do tipo de bico usado e da posição:

- a temperatura superficial exerce influência sobre o avanço da região molhada, modificando as condições de trocas térmicas;

- o valor máximo do coeficiente de transferência de calor ocorre no regime de convecção forçada monofásica;

- o coeficiente de transferência de calor apresenta valor máximo do centro do jato. A diferença no coeficiente de transferência de calor aumenta quanto menor é a pressão usada no resfriamento;

- em temperaturas maiores que $200^{\circ} \mathrm{C}$, a variação pode chegar a $65^{\circ} \mathrm{C}$ entre a superfície e a $10 \mathrm{~mm}$ abaixo dela. Em temperaturas baixas essa variação é mínima, mantendo-se praticamente constante;

- A maior diferença de temperatura encontrada, comparando pressões $2 \mathrm{kgf} / \mathrm{cm}^{2}$ e $19 \mathrm{kgf} / \mathrm{cm}^{2}$, é $90,18^{\circ} \mathrm{C}$.

\section{REFERÊNCIAS}

I Walmag G, Eynde XV, Sinnaeve M, Ernst E. Mechanisms of work rolls degradation in HSM. In: Anais do 44. Seminário de Laminação - Processos e Produtos Laminados e Revestidos; 2007; Campos do Jordão, Brasil. São Paulo: ABM; 2007. p. 904-9I5.

2 Rizzo EMS. Processos de laminação dos aços: uma introdução. São Paulo: Associação Brasileira de Metalurgia e Materiais; 2007. (Capacitação técnica em processos siderúrgicos: laminação).

3 Horský J, Raudenský M, Pohanka M. Optimal cooling of rolls in hot rolling. Journal of Materials Processing Technology. 2002;125-I26:700-705. http://dx.doi.org/I0.1016/S0924-0136(02)00310-2

4 Barbadillo JJ, Trozzi C J. Mechanism of banding in hot strip mill work rolls. Iron and Steel Engineer. 1981;58:63-72. 
5 Shiina K, Nakamura S, Narita K. Cooling characteristics of an impinging spray jet which forms an ellipsoidal liquid film. Heat Transfer: Asian Research. 2000;29:280-299. http://dx.doi.org/I0. I002/(SICl)I523I496(2000)29:4<280::AID-HTJ3>3.0.CO;2-Y

6 Leocádio, H. Resfriamento de uma placa de aço à alta temperatura por meio de um jato de água circular [dissertação de mestrado]. Florianópolis: Universidade Federal de Santa Catarina; 2008.

7 Liu JC, Finn TL, Ramser RA. Average transfer coefficient measurement technique for impinging on spray jets on a rotating cylinder. In: The Winter Annual Meeting of The American Society of Mechanical Engineers. In: I 986; Anaheim, Estados Unidos. In: Padmanabhan M, Dodge, FT, Heidrick TR. Measuring an metering of unsteady flows. New York: ASME, 1986. p. 21-32.

8 Tseng AA, Lin FH, Gunderia AS. et al. Roll Cooling and its relationship to roll life. Metallurgical Transactions: A. 1989;20:2305-2320. http://dx.doi.org// 0.1007/BF02666666

Recebido em: 26/03/2012

Aceito em: 05/06/2013 